\title{
Geography of hospital admissions for multiple sclerosis in England and comparison with the geography of hospital admissions for infectious mononucleosis: a descriptive study
}

\author{
Sreeram V Ramagopalan, ${ }^{1,2,3}$ Uy Hoang, ${ }^{4}$ Valerie Seagroatt, ${ }^{4}$ Adam Handel, ${ }^{1,2}$ \\ George C Ebers, ${ }^{1,2}$ Gavin Giovannoni, ${ }^{3}$ Michael J Goldacre ${ }^{4}$
}

- Additional tables are published online only. To view these files please visit the journal online (http://jnnp.bmj. com).

${ }^{1}$ Wellcome Trust Centre for Human Genetics, University of Oxford, Oxford, UK

${ }^{2}$ Department of Clinical Neurology, University of Oxford, Oxford, UK

${ }^{3}$ Blizard Institute of Cell and Molecular Science, Queen Mary University of London, Barts and The London School of Medicine and Dentistry, London, UK ${ }^{4}$ Unit of Health-Care Epidemiology, Department of Public Health, University of Oxford, Oxford, UK

\section{Correspondence to}

Professor M J Goldacre, Unit of Health-Care Epidemiology, Department of Public Health, University of Oxford Headington, Oxford, OX3 7LF, UK; michael.goldacre@dphpc. ox.ac.uk

SVR and UH contributed equally to this manuscript.

Received 8 October 2010 Accepted 18 October 2010 Published Online First

6 January 2011

\section{ABSTRACT}

Objective It is well recognised that variation in the geographical distribution of multiple sclerosis (MS) exists. Early studies in England have shown the disease to have been more common in the North than the South. However, this could be an artefact of inaccurate diagnosis and ascertainment, and recent data on MS prevalence are lacking. In the present study, data were analysed to provide a more contemporary map of the distribution of MS in England and, as infectious mononucleosis (IM) has been shown to be associated with the risk of MS, the geographical distribution of IM with that of MS was compared.

Methods Analysis of linked statistical abstracts of hospital data for England between 1999 and 2005

Results There were $56681 \mathrm{MS}$ patients. The admission rate for MS was higher in females $\left(22 / 10^{5} ; 95 \% \mathrm{Cl} 21.8\right.$ to 22.3$)$ than males $\left(10.4 / 10^{5} ; 95 \% \mathrm{Cl} 10.2\right.$ to 10.5$)$. The highest admission rate for MS was seen for residents of Cumbria and Lancashire (North of England) (20.1/105;

$95 \% \mathrm{Cl} 19.3$ to 20.8 ) and the lowest admission rate was for North West London residents (South of England) $\left(12.4 / 10^{5} ; 95 \% \mathrm{Cl} 11.8\right.$ to 13.1$)$. The geographical distributions of IM and MS were significantly correlated (weighted regression coefficient $(r(w))=0.70$,

$p<0.0001)$. Admission rates for MS were lowest in the area quintile with the highest level of deprivation and they were also lowest in the area quintile with the highest percentage of population born outside the UK. A significant association between northernliness and MS remained after adjustment for deprivation and UK birthplace.

Conclusions The results show the continued existence of a latitude gradient for MS in England and show a correlation with the distribution of IM. The data have implications for healthcare provision, because lifetime costs of MS exceed $£ 1$ million per case in the UK, as well as for studies of disease causality and prevention.

\section{INTRODUCTION}

Multiple sclerosis (MS) is the most common disease of the central nervous system to cause permanent disability in young adults of Northern European descent. ${ }^{1}$ On the basis of strong circumstantial evidence, MS is thought to be an organ specific autoimmune disorder but much remains to be understood about the initiation of the disease. ${ }^{1} \mathrm{MS}$ seems unlikely to result from a single causative event; instead, the disease seems to develop in genetically susceptible populations as a result of environmental exposures. ${ }^{2}$

The most striking illustration of the importance of the environment in MS is its geographical distribution. ${ }^{3}$ MS prevalence is high in Western Europe and North America, lower in Central and Eastern Europe, Australia and New Zealand, and lowest in Asia, the Middle East and Africa. ${ }^{4}$ Within regions of temperate climate, $\mathrm{MS}$ incidence and prevalence are thought to increase with latitude. ${ }^{3}$ The clearest example of this effect is seen in Australia. The prevalence of MS in Hobart (South Australia) is 75.6 per 100000 compared with a prevalence of 11 per 100000 in Northern Queensland. $^{5}$ The distribution of MS across England has not been investigated since the mid1980s. ${ }^{6}$ Using all available data at that time, a gradient in prevalence was observed between Southern and Northern England. ${ }^{6}$ However, it is not clear how reliable this map of MS prevalence is as methodological concerns have been raised, including differences in diagnostic criteria, meaning that different studies may not be directly comparable. ${ }^{8}$ Given that temporal changes in MS prevalence have occurred, ${ }^{4}$ it would be useful to have a current map of MS across England. This may aid in understanding the aetiology of the disease but equally importantly in facilitating the allocation of healthcare resources given that lifetime costs of MS exceed $£ 1$ million per patient in the UK. ${ }^{9}$

As the risk of MS is increased in individuals with a clinical history of infectious mononucleosis (IM) as a result of Epstein-Barr virus (EBV) infection, ${ }^{10-12}$ we also compared the geography of MS with the distribution of IM.

In this study, we use data from an English national linked Hospital Episode Statistics (HES) database to answer three questions: (1) what is the distribution of admission for MS across England (using the geography of the NHS Strategic Health Authorities); (2) is the distribution of admissions for MS mediated by variations in admission thresholds across England; and (3) is the geography of admission for MS correlated with that for IM in England?

\section{METHODS}

We analysed data on hospital admissions for MS using a file of linked hospital admission statistics, built from the English national HES system by staff of the Oxford University Unit of Health-Care 
Epidemiology, covering all admissions to NHS hospitals in England in the 7 years from 1 April 1998 to 31 March 2005 (population 51 million). The English NHS Central Office for Research Ethics approved the study. We identified cases of MS as code G35 in the 10th revision of the International Classification of Diseases. The English national linked HES database includes information about all people who are admitted to hospital (including day care as well as overnight stays). Using data linkage, we identified each person only once for MS, regardless of how many admissions each person had, and recorded their residence at first known admission for MS.

We show data mainly for the areas of the 28 English strategic health authorities (as they were at the time covered by the data). We also analysed the data at the level of the 352 local authority (LA) areas and the nine government office regions. Admission rates were calculated using numbers of admissions for residents of each area as the numerators and the total resident populations of the area as the denominators. To adjust for differences in the age structure of different areas, age standardisation was undertaken using the indirect method and the age specific rates in 5 year age groups in the English population as the standard. All rates are expressed per 100000 population with 95\% lower and upper confidence limits. Rates were calculated separately for males and females as well as for both sexes combined.

We undertook the same calculations for hospital admissions for people with IM, motor neuron disease (MND), Hodgkin's lymphoma (HL) and non-Hodgkin's lymphoma (NHL) using the International Classification of Diseases codes B27, G12.2, C81 and $\mathrm{C} 82-85$, respectively, to identify them. We analysed the relationship between the length of hospital stays using a Pearson correlation and performed a linear weighted regression to compare the admissions for IM and MS using MATLAB R2009a.

The admission rates by LA were analysed further by grouping them into government office regions as those in Northern regions (the North East, North West, Yorkshire and the Humber regions), Midlands (East Midlands and West Midlands), the East of England region, South East (South East and London regions) and South West. The LAs were ranked according to the Index of Multiple Deprivation and grouped into quintiles of deprivation. The LAs were also ranked according to the percentage of the population 'born outside the UK'. People in England who were born outside the UK are predominantly non-White. We fitted a model to test the effect of quintile of deprivation and quintile of people born outside the UK on admission rated by region.

\section{RESULTS}

\section{Hospital admission for MS}

Table 1 shows the admission rate for MS for both sexes per 100000 resident population for each strategic health authority area. There were 56681 people (39006 females and 17562 males) admitted for MS to hospitals in England in the study period. This produced a national admission rate of 16.4 admissions per 100000 (95\% CI=16.2 to 16.5). This rate was higher in females (22 per 100000 ; $95 \%$ CI 21.8 to 22.3 ) than males (10.4 per $100000 ; 95 \%$ CI 10.2 to 10.5$)$.

\section{Geography of hospital admission for MS}

The highest admission rate for MS was seen from residents of Cumbria and Lancashire (20.1 per 100 000; 95\% CI 19.3 to 20.8) and the lowest admission rate was from North West London residents (12.39 per 100000; 95\% CI 11.77 to 13.05). Geographical distributions were similar for males and females (see supplementary table 1 available online), with North West
London residents having the lowest admission rate for both males and females, Cumbria and Lancashire residents having the highest admission rate for females and residents of Northumberland and Tyne and Wear having the highest admission rate for males.

Figure 1 shows the data from table 1 and supplementary table 1 in map form. The data are shown as quintiles of geographical areas with the one-fifth of areas with the lowest rates shown in the lightest colour and the one-fifth of areas with the highest rates shown in the darkest colour.

\section{Length of hospital stay for MS}

In order to assess whether there is any influence of the length of hospital admission on the geography of admission rates for MS, we compared the geographical distribution of MS for all people with an admission, all with at least one admission including an overnight stay (ie, excluding all day case care), all with at least one stay of 2 days or more and all staying 3 days or more. Our reasoning was that, if geographical differences in admission rates for MS result from differences in clinical admission practice, rather than differences in MS prevalence, the geography of short stay admissions (which may include admissions that are discretionary) might differ from that of longer stay admissions (which probably reflects clinical illness that would warrant admission anywhere). Admission rates in each of these different 'length of stay' categories significantly correlated with each other (minimum Pearson correlation=0.81 (when comparing stays of 3 days or more with all admissions, $p=2 \times 10^{-7}$ ); maximum Pearson $=0.99$ (when comparing stays of 1 day or more with stays of 2 days or more, $\left.\mathrm{p}<1 \times 10^{-30}\right)$ ) (figure 2 ).

\section{Number of admissions per person for MS}

In order to further see if our results are related to thresholds for admission, we took advantage of linked records to identify the number of admissions per patient in each geographical area. The England average was 1.96 spells per patient for MS (range 1.59-3.18). There was no correlation between number of admissions per patient and the standardised person based admission rate per 100000 population in the LAs (weighted regression coefficient $(r(w))=0.06, p=0.73$ ).

\section{Hospital admission for IM}

Table 2 shows the admission rate for IM for both sexes per 100000 resident population for each strategic health authority area. There were 14621 people (6450 females and 8156 males) admitted for IM to hospitals in England in the study period. This produced a national admission rate of 4.2 admissions per 100000 (95\% CI 4.2 to 4.3). This rate was higher in males (4.8 per 100000 ; $95 \%$ CI 4.7 to 4.9 ) than females (3.6 per 100000 ; $95 \%$ CI 3.6 to 3.7 ).

\section{Geography of hospital admission for IM}

The highest admission rate for IM was seen from residents of South Yorkshire (6.60 per 100000 ; 95\% CI 6.08 to 7.15) and the lowest admission rate was in North West London residents (2.31 per 100000 ; 95\% CI 2.06 to 2.59). Geographical profiles were similar for males and females (see supplementary table 2 available online), with North West London residents having the lowest admission rates and residents of South Yorkshire having the highest admission rates for both males and females.

Geographical distributions of hospital admission rates for IM and MS were analysed for any potential correlations (figure 3). Using data for both sexes combined, IM and MS were significantly correlated $(r(w)=0.70, p<0.0001)$. The correlation was 
Table 1 Admission rate for multiple sclerosis per 100000 residents in the strategic health authorities of England

\begin{tabular}{|c|c|c|c|c|c|}
\hline & Strategic health authority & Obs & Exp & $\begin{array}{l}\text { Indirect rate } \\
\text { per } 100000\end{array}$ & $95 \% \mathrm{Cl}$ \\
\hline Rank & All England & 56681 & 56681 & 16.4 & 16.2 to 16.5 \\
\hline 1 & Cumbria and Lancashire & 2743 & 2239.5 & 20.1 & 19.3 to 20.8 \\
\hline 2 & North and East Yorkshire and Northern Lincolnshire & 2304 & 1929.5 & 19.6 & 18.8 to 20.4 \\
\hline 3 & Northumberland, Tyne and Wear & 1926 & 1635.2 & 19.3 & 18.4 to 20.2 \\
\hline 4 & Trent & 3578 & 3100.0 & 18.9 & 18.3 to 19.5 \\
\hline 5 & Norfolk, Suffolk and Cambridgeshire & 2961 & 2582.5 & 18.8 & 18.1 to 19.5 \\
\hline 6 & Dorset and Somerset & 1594 & 1443.4 & 18.1 & 17.2 to 19.0 \\
\hline 7 & Greater Manchester & 3053 & 2817.8 & 17.7 & 17.1 to 18.4 \\
\hline 8 & Avon, Gloucestershire and Wiltshire & 2724 & 2517.3 & 17.7 & 17.1 to 18.4 \\
\hline 9 & Bedfordshire and Hertfordshire & 1925 & 1823.1 & 17.3 & 16.5 to 18.1 \\
\hline 10 & South West Peninsula & 2026 & 1919.6 & 17.3 & 16.5 to 18.1 \\
\hline 11 & South Yorkshire & 1534 & 1458.2 & 17.2 & 16.4 to 18.1 \\
\hline 12 & Kent and Medway & 1893 & 1838.9 & 16.9 & 16.1 to 17.6 \\
\hline 13 & Shropshire and Staffordshire & 1799 & 1763.3 & 16.7 & 15.9 to 17.5 \\
\hline 14 & Surrey and Sussex & 3090 & 3034.5 & 16.7 & 16.1 to 17.3 \\
\hline 15 & County Durham and Tees Valley & 1349 & 1335.8 & 16.5 & 15.7 to 17.4 \\
\hline 16 & Essex & 1879 & 1893.4 & 16.2 & 15.5 to 17.0 \\
\hline 17 & Coventry, Warwickshire, Herefordshire & 1727 & 1802.9 & 15.7 & 15.0 to 16.4 \\
\hline 18 & Cheshire and Merseyside & 2583 & 2737.5 & 15.5 & 14.9 to 16.1 \\
\hline 19 & West Yorkshire & 2173 & 2316.9 & 15.4 & 14.7 to 16.0 \\
\hline 20 & South East London & 1431 & 1614.1 & 14.5 & 13.8 to 15.3 \\
\hline 21 & Hampshire and Isle of Wight & 1812 & 2060.9 & 14.4 & 13.7 to 15.1 \\
\hline 22 & Leicestershire, Northamptonshire and Rutland & 1539 & 1781.0 & 14.1 & 13.5 to 14.9 \\
\hline 23 & Birmingham and the Black Country & 2136 & 2490.4 & 14.0 & 13.5 to 14.7 \\
\hline 24 & Thames Valley & 1988 & 2372.6 & 13.7 & 13.1 to 14.3 \\
\hline 25 & North Central London & 1058 & 1273.6 & 13.6 & 12.8 to 14.4 \\
\hline 26 & North East London & 1280 & 1550.5 & 13.5 & 12.8 to 14.3 \\
\hline 27 & South West London & 1118 & 1422.4 & 12.9 & 12.1 to 13.6 \\
\hline 28 & North West London & 1458 & 1926.2 & 12.4 & 11.8 to 13.0 \\
\hline
\end{tabular}

Data in rank order of admission rates

Obs, observed number of people; Exp, expected number.

similar when studying just females $(r(w)=0.69, p<0.0001)$ and slightly weaker when studying just males $(r(w)=0.63$, $\mathrm{p}=0.0003)$. This correlation was weaker when looking at the data when divided into the 352 LAs $(r(w)$ both sexes $=0.47$, $p<0.0001)$ and stronger (but less significant) when divided into the nine government office regions $(r(w)=0.84, p=0.004)$ (see supplementary tables 3 and 4 available online).
As a control, we also investigated the geographical distributions of hospital admissions for MND, HL and NHL for correlations with the geographical distributions of MS and IM. Using data for both sexes combined, the correlation for MS with MND was significant $(\mathrm{r}(\mathrm{w})=0.41, \mathrm{p}=0.03)$ but not significant with HL or NHL $(r(w)=-0.26, p=0.18 ; r(w)=-0.2, p=0.3$, respectively). The correlation for IM with MND was non-significant
A

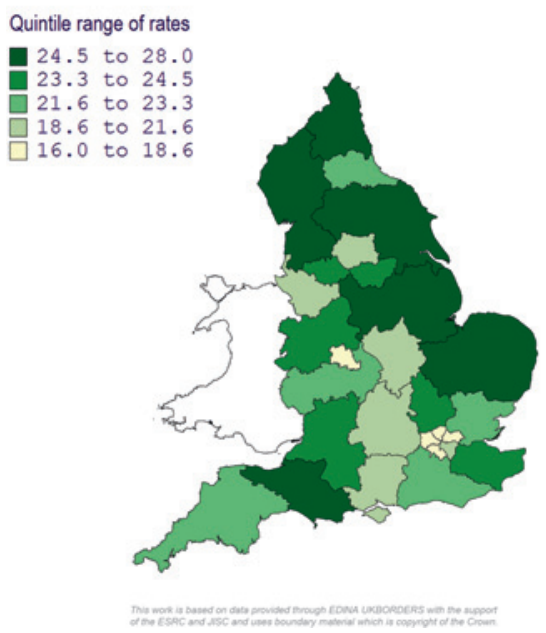

B

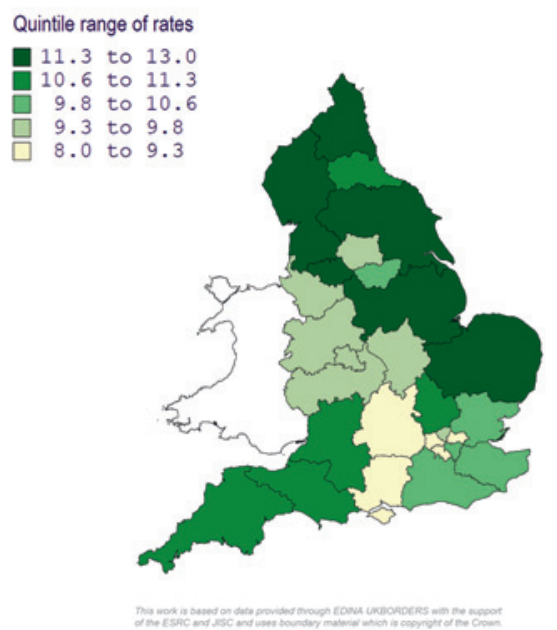

C

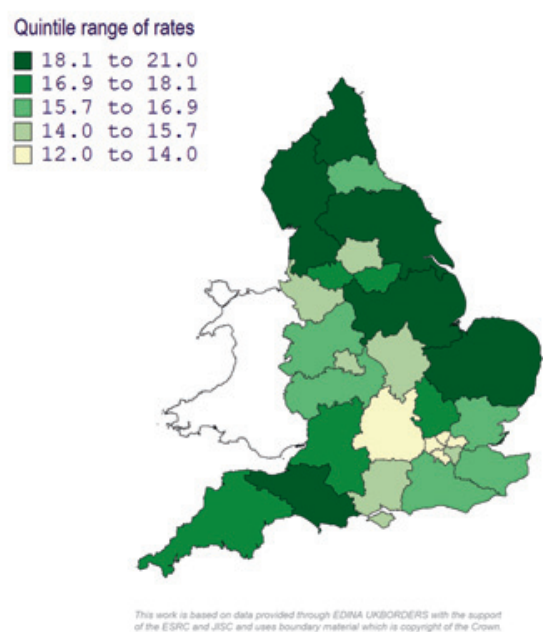

Figure 1 Geographical distribution of hospital admission for multiple sclerosis (MS) for (A) females, (B) males and (C) both sexes, showing strategic health authorities. 


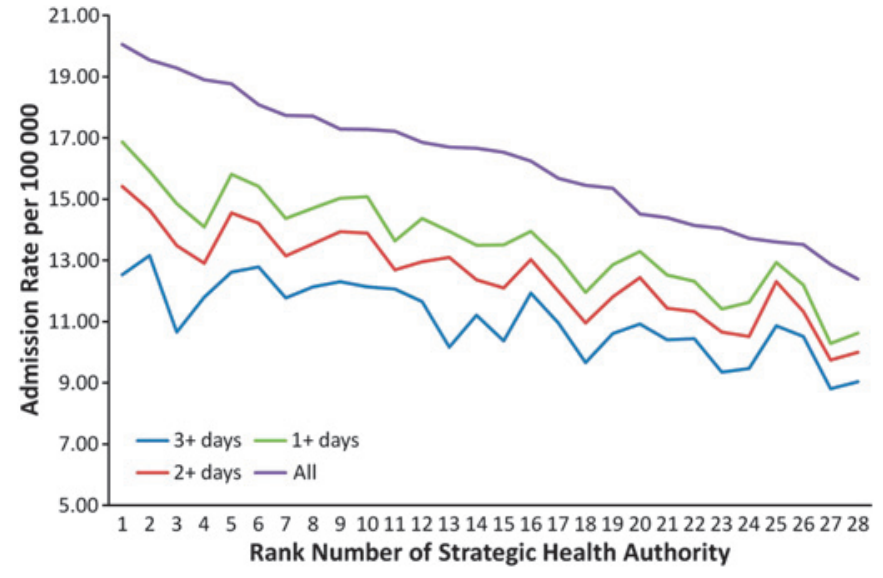

Figure 2 Distribution of hospital admission rates by region according to length of hospital stay. Rank number refers to rank number of strategic health authority in table 1.

$(\mathrm{r}(\mathrm{w})=0.23, \quad \mathrm{p}=0.25), \quad$ significant with $\mathrm{HL} \quad(\mathrm{r}(\mathrm{w})=-0.38$, $\mathrm{p}=0.048)$ and non-significant with NHL $(\mathrm{r}(\mathrm{w})=-0.05, \mathrm{p}=0.8)$.

\section{Geography of hospital admissions for MS adjusting for deprivation and ethnicity}

When looking at the five broad areas of England, the highest admission rate was in the North, at $23 \%$ higher than the national average, and the lowest was the South East (table 3). There was no consistent trend with deprivation: the lowest rates for $\mathrm{MS}$ in the five quintiles were in the first (least deprived) quintile and the fifth (most deprived) quintile. Considering place of birth, as a proxy for ethnicity, the lowest admission rate for MS was in the quintile with the highest percentage of the population born outside the UK. The North of England remained the region with the highest rate after adjustment for deprivation and (presumed) ethnicity (table 3). After adjustment of each factor for the other two, the four upper quintiles of deprivation had significantly higher levels of risk than the lowest quintile (ie, high deprivation was associated with low risk of $\mathrm{MS}$ ). Adjustment also confirmed that the quintile with the highest percentage of the population born outside the UK had the lowest risk of MS.

\section{DISCUSSION}

We present here the most up to date available map of the distribution of MS in England, using data from a single source. This method contrasts with previous work on the distribution of MS in England that used a compilation of data from different published studies and differing methods of case ascertainment. ${ }^{6}$ In general, our data indicate a gradient in the frequency of the disease between Southern and Northern England. This distribution is not related to lengths of hospital stay or number of admissions per patient, markers for disease severity and threshold for admission. The distribution of MS across England is also significantly correlated with the distribution of IM, especially in females. This correlation is not a general phenomenon as no significant correlation was seen with HL, NHL and

Table 2 Admission rate for infectious mononucleosis per 100000 residents in the strategic health authorities of England

\begin{tabular}{|c|c|c|c|c|}
\hline Strategic health authority & Obs & Exp & $\begin{array}{l}\text { Indirect rate } \\
\text { per } 100000\end{array}$ & $95 \% \mathrm{Cl}$ \\
\hline All England & 14621 & 14621 & 4.2 & 4.2 to 4.3 \\
\hline South Yorkshire & 595 & 380.7 & 6.6 & 6.1 to 7.2 \\
\hline South West Peninsula & 612 & 433.3 & 6.0 & 5.5 to 6.5 \\
\hline Kent and Medway & 628 & 459.6 & 5.8 & 5.3 to 6.2 \\
\hline Trent & 1031 & 761.5 & 5.7 & 5.4 to 6.1 \\
\hline Dorset and Somerset & 402 & 321.2 & 5.3 & 4.8 to 5.8 \\
\hline Norfolk, Suffolk and Cambridgeshire & 768 & 617.0 & 5.3 & 4.9 to 5.6 \\
\hline Essex & 564 & 454.5 & 5.2 & 4.8 to 5.7 \\
\hline North and East Yorkshire and Northern Lincolnshire & 564 & 470.6 & 5.1 & 4.7 to 5.5 \\
\hline County Durham and Tees Valley & 404 & 346.6 & 4.9 & 4.5 to 5.4 \\
\hline Northumberland, Tyne and Wear & 480 & 418.0 & 4.9 & 4.4 to 5.3 \\
\hline Hampshire and Isle of Wight & 566 & 527.4 & 4.5 & 4.2 to 4.9 \\
\hline Surrey and Sussex & 712 & 693.1 & 4.3 & 4.0 to 4.7 \\
\hline Shropshire and Staffordshire & 442 & 433.7 & 4.3 & 3.9 to 4.7 \\
\hline Avon, Gloucestershire and Wiltshire & 623 & 628.8 & 4.2 & 3.9 to 4.5 \\
\hline Cheshire and Merseyside & 680 & 704.3 & 4.1 & 3.8 to 4.4 \\
\hline Cumbria and Lancashire & 530 & 556.6 & 4.0 & 3.7 to 4.4 \\
\hline Bedfordshire and Hertfordshire & 438 & 468.0 & 4.0 & 3.6 to 4.3 \\
\hline Greater Manchester & 731 & 782.8 & 3.9 & 3.7 to 4.2 \\
\hline Leicestershire, Northamptonshire and Rutland & 441 & 477.6 & 3.9 & 3.5 to 4.3 \\
\hline Coventry, Warwickshire, Herefordshire & 408 & 442.2 & 3.9 & 3.5 to 4.3 \\
\hline West Yorkshire & 535 & 654.5 & 3.5 & 3.2 to 3.8 \\
\hline Birmingham and the Black Country & 581 & 715.8 & 3.4 & 3.2 to 3.7 \\
\hline Thames Valley & 477 & 640.2 & 3.1 & 2.9 to 3.4 \\
\hline South West London & 260 & 376.9 & 2.9 & 2.6 to 3.3 \\
\hline North Central London & 249 & 369.8 & 2.8 & 2.5 to 3.2 \\
\hline South East London & 294 & 452.0 & 2.7 & 2.4 to 3.1 \\
\hline North East London & 310 & 493.2 & 2.7 & 2.4 to 3.0 \\
\hline North West London & 296 & 541.0 & 2.3 & 2.1 to 2.6 \\
\hline
\end{tabular}

Data in rank order of admission rates.

Obs, observed number of people; Exp, expected number. 

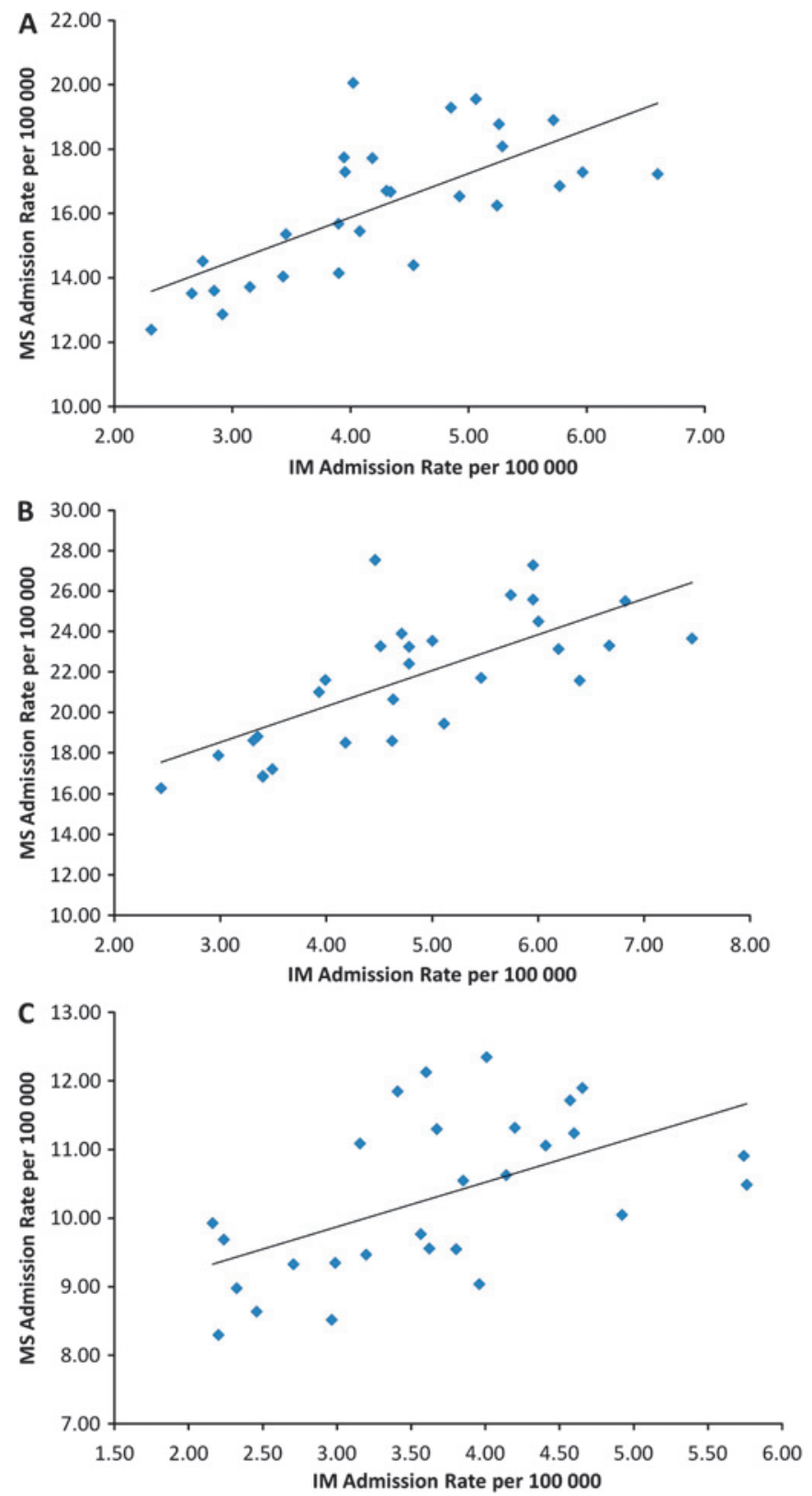

Figure 3 Scatter plots for admissions per 100000 for infectious mononucleosis (IM) and multiple sclerosis (MS) in (A) both sexes, (B) females and (C) males.

a much weaker correlation was observed with MND. Early studies have suggested that MS is a disease primarily affecting those in a higher socioeconomic status, ${ }^{13}$ and therefore geographical findings could be confounded by socioeconomic status. However, taking account of deprivation indices had little effect on our results, highlighting that socioeconomic factors do not appear to be a major influence on hospital admissions for MS.

The extent of geographical variation is fairly modest: at about $20 \%$ between highest and lowest region, it is considerably less than that found for coronary heart disease, for example.

It is likely that some genetic differences exist between Northern and Southern English populations but this does not appear to be the main explanation behind regional differences in MS period prevalence. ${ }^{6}$ The similarities between the epidemiology of MS and IM were noted more than two decades ago ${ }^{14}$
Table 3 Relative risk for multiple sclerosis admission in each area, deprivation quintile and place of birth quintile, and relative risk for each factor after adjusting for the other two

\begin{tabular}{lllll}
\hline Area & $\begin{array}{l}\text { Unadjusted } \\
\text { RR }\end{array}$ & $\begin{array}{l}\text { Adjusted } \\
\mathbf{R R}\end{array}$ & $\begin{array}{l}\text { Lower } \\
\mathbf{9 5 \%} \mathbf{~ C l}\end{array}$ & $\begin{array}{l}\text { Upper } \\
\mathbf{9 5 \%} \mathbf{~ C I}\end{array}$ \\
\hline North & 1.23 & 1.19 & 1.11 & 1.28 \\
$\quad$ Midlands & 1.11 & 1.05 & 0.99 & 1.12 \\
$\quad$ East & 1.17 & 1.12 & 1.05 & 1.19 \\
South East/London & 1.00 & 1.00 & & \\
$\quad$ South West & 1.20 & 1.12 & 1.04 & 1.20 \\
Index of Multiple Deprivation quintiles & 1.01 & 1.08 & 1.01 & 1.16 \\
1 (least deprived) & 1.10 & 1.12 & 1.05 & 1.19 \\
2 & 1.10 & 1.12 & 1.05 & 1.19 \\
3 & 1.07 & 1.07 & 1.01 & 1.14 \\
4 & 1.00 & 1.00 & & \\
5 (most deprived) & & & & \\
Percentage born outside UK-quintile & 1.24 & 1.12 & 1.04 & 1.20 \\
1 (lowest \% born out of the UK) & 1.24 & 1.12 & 1.04 & 1.20 \\
2 & 1.18 & 1.09 & 1.02 & 1.16 \\
3 & 1.16 & 1.10 & 1.03 & 1.16 \\
4 & 1.00 & 1.00 & & \\
\hline (highest \% born out of the UK) & 1.00 & & &
\end{tabular}

Cls for the adjusted relative risk (RR).

and we show for the first time that a correlation exists for the distribution of MS and IM in England. This correlation is stronger for females and indeed there is evidence to suggest that a history of IM may confer differential risk for MS depending on gender. ${ }^{15}$ Thus both genes and EBV are implicated in the geography of $\mathrm{MS}$ but sunlight exposure and associated vitamin $\mathrm{D}$ status are also likely to be a major influence for the association between latitude and MS period prevalence in England. ${ }^{2}$ Interestingly, HL was not associated with MS admissions, highlighting potential differences of EBV effects in IM and HL, and subsequent influences on MS risk.

MS imposes a significant burden on healthcare costs, work related productive capacity, quality of life and life expectancy of those affected. An accurate understanding of epidemiological characteristics of MS may not only provide insights into possible disease causes and pathogenesis, but also have implications in healthcare strategies, public health recommendations and focus of research efforts. At present there are no effective vaccines or treatments targeting EBV, leaving vitamin D supplementation as the only available intervention that might result in a reduction in the prevalence of this often devastating disease. ${ }^{16}$

There are limitations to our data. Many factors can influence MS admission rates. Although we have attempted to control for this by studying length of stay and number of admissions per patient, clinical practice preferences may still exist in the threshold for admission, definition of relapses and type of treatment. There may also be differences in the availability of resources, including numbers of specialist MS staff which can affect inpatient versus outpatient management. Furthermore, our data may imply more severe, rather than more prevalent, MS in the North of England, hence more hospitalisations. Limitations of record linkage studies using routinely collected administrative data are well known, and include the facts that the data are limited to hospitalised patients and that information about some variables of potential interest are generally unavailable. We did not have data at the level of individual people on ethnicity or socioeconomic status but did our best to control for this by analysing the aggregate level data for LAs. Accounting for the proportion of people born outside of the UK will exclude individuals with generally the lowest risk of MS, as 
the incidence of MS in second generation migrant populations in the UK is on the rise. ${ }^{17}$ Deprivation scores reflect the socioeconomic status of the local community and may not wholly reliably reflect the status of individuals in our study within each community. We only analysed hospitalisation for IM and thus we would underestimate milder cases of IM. However, it may also be that more severe cases of IM increase the risk of MS to a greater extent than milder cases.

In conclusion, the distribution of MS across England shows significant although modest variation, at least as measured by hospitalisation rates. The higher rates in the North than the South of England persist; they are consistent with earlier findings from studies in different parts of the UK and they are consistent with the more general finding across the world that MS prevalence increases with increasing distance from the equator in both hemispheres. The distribution in England is not a result of any simple known causative association. Some of the factors that may be implicated are increasingly recognised-exposure to solar radiation and perhaps late infection with EBV-and no doubt there are other unknown factors affecting geographical profiles of hospitalisation. The reasons for the high period prevalence in the North of England need to be uncovered.

Acknowledgements The authors thank colleagues at the University of Oxford for helpful comments.

Funding This work was funded by the English National Institute for Health Research, the Multiple Sclerosis Society of Great Britain and Northern Ireland, the Medical Research Council and the Wellcome Trust (grant No 075491/Z/04). SVR is a Goodger Scholar at the University of Oxford. UH is an Academic Clinical Fellow at the Oxford University Clinical Academic Graduate School.

\section{Competing interests None.}

Ethics approval This study was conducted with the approval of the Central and South Bristol REC.
Provenance and peer review Not commissioned; externally peer reviewed.

\section{REFERENCES}

1. Noseworthy JH, Lucchinetti C, Rodriguez M, et al. Multiple sclerosis. N Engl J Med 2000; $343: 938-52$

2. Ebers GC. Environmental factors and multiple sclerosis. Lancet Neurol 2008:7:268-77.

3. Pugliatti M, Sotgiu S, Rosati G. The worldwide prevalence of multiple sclerosis. Clin Neurol Neurosurg 2002;104:182-91.

4. Koch-Henriksen N, Sorensen PS. The changing demographic pattern of multiple sclerosis epidemiology. Lancet Neurol 2010;9:520-32.

5. Hammond SR, McLeod JG, Millingen KS, et al. The epidemiology of multiple sclerosis in three Australian cities: Perth, Newcastle and Hobart. Brain 1988:1:1-25.

6. Swingler RJ, Compston D. The distribution of multiple sclerosis in the United Kingdom. J Neurol Neurosurg Psychiatry 1986:49:1115-24.

7. Forbes RB, Swingler RJ. Estimating the prevalence of multiple sclerosis in the United Kingdom by using capture-recapture methodology. Am J Epidemiol 1999;149:1016-24.

8. Compston A, McAlpine D. McAlpine's Multiple Sclerosis. 4th Edn. Philadelphia, PA Churchill Livingstone/Elsevier, 2005.

9. McCrone $\mathbf{P}$, Heslin M, Knapp M, et al. Multiple sclerosis in the UK: service use, costs, quality of life and disability. Pharmacoeconomics 2008;26:847-60.

10. Thacker EL, Mirzaei F, Ascherio A. Infectious mononucleosis and risk for multiple sclerosis: a meta-analysis. Ann Neurol 2006;59:499-503

11. Ramagopalan SV, Valdar W, Dyment DA, et al. Association of infectious mononucleosis with multiple sclerosis. A population-based study. Neuroepidemiology 2009;32:257-62

12. Goldacre MJ, Wotton CJ, Seagroatt V, et al. Multiple sclerosis after infectious mononucleosis: record linkage study. J Epidemiol Community Health 2004; 58:1032-5

13. Russell WR. Multiple sclerosis: occupation and social group at onset. Lancet 1971;2:832-4.

14. Ascherio A, Munger KL. Environmental risk factors for multiple sclerosis. Part I: the role of infection. Ann Neurol 2007:61:288-99.

15. Ahlgren C, Toren $\mathrm{K}, \mathrm{Oden} \mathrm{A}$, et al. A population-based case-control study on vira infections and vaccinations and subsequent multiple sclerosis risk. Eur J Epidemiol 2009:24:541-52

16. Ascherio A, Munger KL, Simon KC. Vitamin D and multiple sclerosis. Lancet Neurol 2010:9:599-612.

17. Dean G, Elian M. Age at immigration to England of Asian and Caribbean immigrants and the risk of developing multiple sclerosis. J Neurol Neurosurg Psychiatry 1997;63:565-8. 